\title{
Effects of the Deregulation of Supervision on the Selling of Insurance
}

\author{
by Edgar Jannott*
}

\section{Introduction and basic issues}

When examining the Brussels EC Recommendation on Intermediaries of 18th December 1991, one gains the impression that against a background of wide-ranging deregulation of insurance law, the selling of insurance will not be deregulated, but on the contrary, will actually be subject to stricter regulation. At first sight therefore the Brussels Recommendation on Intermediaries appears to strike a discordant note amidst our general deregulatory euphoria. At the very least, liberal economists - and perhaps liberal legislators as well - must find it well nigh intolerable in the context of virtually unrestrained endeavours towards liberalization and deregulation to apply stricter regulations to the selling of insurance.

However, before reaching a definitive conclusion on this subject, it will be helpful to examine its context with knowledge of the relevant background.

What is the context and the setting in which the politicians in Brussels are recommending European legislators to create at least a partial regulatory framework for insurance intermediaries? In the first place, it is essential that we consider the deregulation of supervision and of product development, so as to understand the connections.

\subsection{Deregulation of supervision}

The EC Life Assurance and Non-Life Insurance Directives - which are now being implemented by the individual EC States, including here in Germany - are based on a uniform and single authorization of insurance undertakings by the respective home country. It is from there that these undertakings' activities throughout the European internal market are to be monitored.

In practice this means that a Portuguese insurer, who sells you a household insurance policy in Mannheim on the 2nd July 1994, is subject to Portuguese, not German, supervision. If on the 3rd July 1994 you realise that you have not been properly served by the Portuguese insurer you can then no longer make a complaint to the German supervisory

\footnotetext{
* Chief Executive of the Victoria Group; speech given by Dr. Edgar Jannott on the 13th April 1994 at the annual meeting of the Association for the Promotion of Insurance Studies and the Mannheim University Institute for Insurance Studies.
} 
authority, but would have to direct this at the Portuguese insurer in Portugal or at the supervisory authority there. If by chance you cannot speak Portuguese, it is conceivable that the German supervisory authority may nonetheless offer assistance, in so far as they are able to from the staffing and language points of view. Conversely of course any Portuguese citizen who is sold a product there by a German insurer, will have to turn to the German supervisory authority if he has a complaint. Whether the German supervisory authority understands Portuguese or whether the Portuguese supervisory authority can at least be of linguistic assistance to the German authority is not something I can express an opinion on.

\subsection{Deregulation of product development}

The EC Directives already mentioned require, amongst other things, the ending of the requirement for prior approval of insurance conditions and premium rates. This means that our supervisory authority will no longer examine conditions and premium rates of products before they are made available, as has so far been the case. In future every insurer can bring products into the market whose conditions and premium rates have not been examined.

There can be no doubt that removing compulsory approval of premium rates and conditions will increase competition and product diversity. Whereas until now our supervisory authority was concerned so far as possible to approve only uniform premium rates and conditions based on model conditions and business plans, in future every insurer will make use of his entrepreneurial freedom in designing conditions and premium rates. He will tailor his product in accordance with his own attitudes and the risk he is prepared to accept and carry. Of course we can expect that German insurers will not only focus on their own attitudes but also primarily on those of their customers. In any case however the removal of premium rates and conditions approval will reduce the comparability and transparency of insurance products, something that has always been particularly promoted until now. This will be replaced by non-comparability and by a lack of transparency of insurance products which will soon dominate the market.

To summarise :

- Every insurer who has been authorized in any one EC country can in future transact business on a cross-border basis throughout the whole European internal market.

- Supervision will be more remote from the consumer. Supervision by the country of origin means long-distance supervision instead of local supervision.

- The quality of product approval will change. There will no longer be a general requirement for the supervisory authority's prior approval, only the judicial right to subsequent court examination of products in particular cases.

- Consumer protection is no longer provided by professionally trained officials, but by competition between companies and by consumers' own knowledge.

- Consumer protection is no longer based on supervision of comparably designed products, but will be complicated by their variety. Instead of product transparency, lack of transparency of products will increase.

\section{Effects on the intermediaries}

It is obvious that the sweeping changes in the insurance market described above will have a very significant impact on the activities of intermediaries. Time restrictions prevent me here from examining two particular problems of deregulation that will especially affect 
the intermediaries market and bring about additional changes. I am referring here to the proposed ending of the prohibitions on sharing commission and on preferential terms. As however no definite conclusions have yet been reached on these two matters, this reference must suffice.

Supervision, the insurance industry, product development and consumers are all about to enter a new age.

Intermediaries too? Yes, intermediaries as well. The deregulated market with its unapproved products, the greater variety of available products, supervision from abroad by the authorities in the country of origin and the problems of language differences will inevitably also call for a greater amount of professional advice from intermediaries and thus for a very different qualification standard from previously. Consumers and customers will more frequently seek - and above all need - the help and advice of intermediaries. In future therefore every insurance intermediary will have to undergo a much more intensive professional training programme. All those wishing to maintain their place in the market and safeguard their livelihood as intermediaries will only succeed by demonstrating that they have the necessary professional competence in a competitive market. The new insurance environment that we enter on the 1st July 1994 will require a very different looking insurance intermediaries profession than before.

What should the insurance intermediaries profession look like in this new environment?

The Intermediaries Directive in the 70's was a signal from the European Community reformers that insurance intermediaries just as much as insurance undertakings should naturally be able to - and indeed ought to - carry out their professional activities throughout Europe. However the EC Commission's original intention was for insurance law to be standardized throughout Europe. Cross-border activities of the intermediaries as well as their authorization conditions would thus have been facilitated. We all know that the EC Commission's original idea has not been realized. The lofty goal of standardizing insurance law throughout Europe could not be attained. What has emerged is only a partial harmonisation.

This partial harmonisation has not achieved standardized consumer protection in terms of supervision and product development. In recognition of this the EC Commission has made clear in its Recommendation on Intermediaries of 18th December 1991 that at least as far as intermediaries are concerned, certain common standards for professional competence, good reputation and registration should be assured throughout Europe by means of a framework of regulations in the individual EC States. It would be correct to see this Recommendation on Intermediaries as a consumer protection measure that seemed necessary to the Brussels Commission in the light of the actual situation which they themselves had created.

What does the Recommendation on Intermediaries look like in detail? To appreciate it correctly, one should be aware that its formulation was presided over by the British EC Commissioner, Sir Leon Brittan. It is therefore not surprising that the Recommendation is largely based on British ideas. The Recommendation states that Member States should stipulate professional standards and require the registration of insurance intermediaries; by the end of 1994 the EC Commission is to be informed of the measures adopted to put the Recommendation into practice. 


\section{Main points of the recommendation on intermediaries}

The following paragraphs briefly examine the details regarding scope of individual professional activity, the professional standards to be set, the duty of registration and sanctions.

\subsection{Scope of individual professional activity}

The Recommendation is concerned with "insurance intermediaries", i.e. persons who act in this capacity either on a self-employed basis or as paid employees. According to German Law, all self-employed intermediaries and all employees acting as insurance intermediaries are therefore included. Member States may exempt persons who act as insurance intermediaries only incidentally to another commercial activity. The German insurance industry hopes that this arrangement will allow those acting as part-time insurance intermediaries to be excluded from the scope of the Recommendation. Persons acting as parttime intermediaries on an occasional basis naturally should not have to meet the same standards as those required for a full-time professional intermediary. It would even be advisable from the point of view of consumer protection if those acting as part-time intermediaries were not included in the Recommendation and would thus be clearly distinguished from the full-time intermediaries. Finally the Recommendation makes certain allowances for undertakings acting as insurance intermediaries. However Member States should work towards these undertakings offering appropriate basic training to those of their employees working in insurance intermediary.

\subsection{Strict separation between company insurance agents and indepedent brokers}

A central point of the Recommendation is the strict separation between tied insurance company agents (i.e. employees working as sales representatives and self-employed singleor multi-company agents) and independent brokers. This principle of "Polarisation" derives from the UK's Financial Services Act. The consumer should know from the start with which type of intermediary he is dealing. This is important for him, particularly in connection with the question of liability. The Recommendation applies special conditions to brokers. They must make it clear to the consumer that they are genuinely independent and have complete freedom of choice of insurance undertakings. In addition they must have professional indemnity insurance. As is known, brokers are themselves liable for any wrong advice they give, whereas in the case of agents, the insurance company is liable.

\subsection{Professional competence}

The Recommendation only states that insurance intermediaries should possess "general, commercial and professional knowledge and ability". The Recommendation itself does not contain more precise details e.g. about what training is necessary for the intermediary. Such details are rather left for the Member States - and this is decisive for the German market - for the local professional organisations to determine. I will explain in a moment why this is so important, but before that, I briefly conclude this description of the contents of the EC Recommendation.

\subsection{Registration}

Insurance intermediaries who fulfil the stipulated requirements are to be entered in a central register of intermediaries. Only persons on this register may act as intermediaries. The register should differentiate between tied company agents and independent brokers. 
Insurance intermediaries are to disclose their registration, for example on letter heads, etc. Here too it is important for the German market that this register does not have to be administered by the State, but may also be maintained by an approved professional organisation.

\subsection{Sanctions}

Finally, the Recommendation on Intermediaries provides for Member States to lay down sanctions. These are to prevent persons who are not registered from acting as in surance intermediaries. In addition, intermediaries who are entered in the register but who no longer fulfil the requirements for professional competence may be penalised and removed from the register.

\section{Proposals of the German insurance industry for the adoption of the Recommendation}

In view of the Recommendation's contents it will rigthly be expected that the insurance industry will have given consideration to and developed plans for the adoption of this Recommendation by means of its existing institutions and facilities. If the industry's own facilities and institutions are used, then critics who are not well disposed to the industry could again draw negative conclusions from this. Such criticism could be countered by the fact that the Recommendation on Intermediaries proposes the utilization of existing facilities and institutions precisely because of the wish to retain and continue using tried and tested means. Furthermore it is the only way of conforming to the governing principle of our age of deregulation: namely as much self-initiative as possible and only so much State involvement as is absolutely necessary.

\subsection{Professional training}

In 1990 the German insurance industry set up a uniform training programine for insurance intermediaries. All newcomers to this profession participate in this "basic training". This training course leads to qualification as an "Insurance Specialist" ("Versicherungsfachmann BWV") and was devised by the Professional Training Organisation ("BWV") of the German insurance industry. The course envisages a one year minimum period of training comprising a theoretical and a practical component. Here the new intermediary learns, amongst other things, about the fundamental technical principles of all classes of personal business lines. The training itself is carried out in the respective insurance undertakings. To the companies this requires a considerable investment - the training costs alone amount to some DM 40,000 for each intermediary. At the end of the training period the new intermediary must undergo a two days examination before an industry-wide examination committee of the Professional Training Organisation. If he passes this, he receives a certificate and a photo identity card with which he can prove to customers that he is a qualified "insurance specialist".

This training programme is now operating throughout the industry and in every part of the country. I see it as an exceptional success that all German insurance undertakings are now participating in the training programme of the Professional Training Organisation. This can only be due to the fact that all concerned are convinced of its benefits. When acknowledging this success, it should not be overlooked that the hundreds of insurance companies competing in the German market have all joined forces here in this joint undertaking. One should also be aware that the decision to participate in this training programme requires an investment by each company (according to its size) of several - or in most cases, many - millions of Deutschmarks. In addition, there are the inevitable difficulties connected 
with every training programme - such as unfair assessments, "failure" rates, etc. - which result in internal disputes with individuals, staff associations, etc. This is particularly relevant as the "failure" rate for the approximately 25,000 examinations that have so far been carried out is around $20 \%$. At the same time this rate shows that the process is not a cosmetic one, but is truly selective. Because this training programme is taken so seriously by all German insurance undertakings, the intermediaries' associations, trade unions and the Federal Office for Insurance Supervision have all so far given it their unqualified support.

So much for the German insurance industry's proposals as to how the EC Recommendation regarding evidence of the intermediary's professional competence should be put into effect. However the Recommendation also requires the registration of intermediaries.

\subsection{Register of intermediaries}

The Information Bureau for Insurance Sales Representatives has existed for a long time in the Federal Republic. This is a self-protection organisation of the industry, set up shortly after the end of the Second World War. The purpose of the Bureau is to prevent unsuitable persons from working as insurance intermediaries and it provides an information exchange service. This means that every insurance undertaking newly employing an intermediary must check with the Bureau whether anything is known to his detriment. If this is not the case, and if as a minimum proof that he is reputable a police certificate can be submitted confirming the absence of a criminal record, then there is nothing further to prevent his employment. The Bureau must also be informed when he commences employment and later on when his employment ceases. The Bureau has proved most useful and is supported by the Federal Office for Insurance Supervision; above all, this exchange of information accords with data protection requirements. The Bureau is also a recognised professional organisation in terms of the EC's Recommendation on Intermediaries. As a result of the long practical experience of the information exchange, nearly every insurance intermediary working in the market is registered with the Bureau. For these reasons the Bureau (or a sub-organisation of the Bureau) really would be predestined to become the central register of insurance intermediaries in the Federal Republic.

Concrete plans already exist to form, with the Bureau's cooperation, a new organisation that will act as a register of intermediaries, to be called the "Central Register of Insurance Intermediaries in Germany". The Register, which will be accessible to every consumer, will differentiate between tied company agents and brokers. It will also record basic data about the intermediary that is unproblematic from the data protection point of view, such as: Family Name, First Name, Date of Birth, etc., as well as specific professional data, such as extent of training, existence of professional indemnity insurance, etc. This is the German insurance industry's proposal on the question of registration.

\section{Acknowledgement of legislators' attitudes to date}

In view of the measures already in place, or initiatives already planned by the industry, one would think it easy for the German legislators to implement the necessary legal framework for insurance intermediaries in accordance with the EC Recommendation. Unfortunately this is far from the case : precisely because the industry has already provided its own solution, the Federal government is of the opinion that a legal framework is unnecessary. The government points to the industry's existing solution and declares that all is right with the world. In doing so, its interpretation of the phrase "as much self-initiative as possible 
and only so much State involvement as is necessary" is that because all is right with the world, nothing needs to be done. However this is in extreme contrast to the fact that problems arising from the misselling of insurance are constantly being criticised by certain politicians and others, and furthermore that self-protection organisations crcated by an industry consisting of undertakings competing fiercely with each other cannot last forever.

The government's line docs not therefore seem to me to be the right one. I cannot understand the government's reticence in this matter. Insurance is a "particularly sensitive area" according to the judgement of the European Court of Justice and because of this the Court considers that consumer protection is very important.

It is in the nature of insurance products that they are not tangible ; they are intangible promises of performance. In both senses of the word, these promises cannot be "grasped". Yet these intangible insurance products can sometimes be much more dangerous than many other products. The wrong pension product, incomplete health insurance, gaps in cover of a liability insurance expose the individual to greater dangers than do other, tangible products. Furthermore, other products can usually be tested immediately, whereas insurance products only over the years.

I am therefore of the opinion that the EC Commission's Recommendation is quite right to bring the level of quality of insurance intermediaries into line with this new situation by deeming greater professional competence and registration necessary. One must also remember that all other physical and tangible products may only be produced according to fixed "DIN" or "RAL" standards or may only be allowed onto the market after "TÜV" approval. In addition there are also usually legal conditions relating to the sale of these products. If one decides to allow intangible insurance promises onto the market in the form of unapproved products, then at least it is advisable to set minimum standards for selling these products.

Let us be quite clear on this: the insurance industry does not want comprehensive and detailed regulations for authorization of insurance intermediaries nor statutory codes of conduct. What it would like is for German legislators to make use of the opportunity already provided by the EC. Recommendation on Intermediaries to implement a legal framework that will safeguard and formalise the industry's existing system. Our Professional Training Centre and the Information Bureau are a response to the current situation and common sense; lack of State recognition and tough competition between undertakings could quickly spell their end.

A legal framework would oblige the insurance industry to preserve these institutions. This could be done by adding a clause to the Law of Insurance Supervision, that in so far as full-time intermediaries are concerned, insurance undertakings may only work with such persons as possess sufficient professional competence, who have been included in a central register and who can also show they are of good repute e. g. by police confirmation that no criminal record exists. The Ministry of Economic Affairs and the Federal Office for Insurance Supervision could then provide more detailed regulations. These could state that insurance intermediaries may be deemed to have sufficient professional competence, if they have at least successfully completed their training as "insurance specialists". In addition they could require the insurance intermediaries' register to be administered by the Information Bureau or an associated organisation. Finally one would also need to consider where 
best to include the sanctions proposed by the EC Recommendation on Intermediaries. The inclusion of an infringement clause in the Law on Insurance Supervision could be considered.

\section{Advantages of a legal framework integrating the industry's own solutions}

The approach I have described here seems to me to be the golden mean. On the one hand the EC Recommendation on Intermediaries would be put into effect using the industry's own resources, on the other hand other sectors of the economy would not be prejudiced. The adoption of the EC Recommendation in this way would not be contrary to the efforts towards deregulation and would keep the State's involvement to the necessary minimum.

Until now the government could not be won over to what is in my view a convincing solution. In particular they are afraid that if they concede on the Recommendation on Intermediaries, other professions will also demand legal regulations governing professional conduct.

I am well aware that for many years the German insurance industry has spoken out against legal regulations governing the authorization and professional conduct of insurance intermediaries. For a long time German insurance companies and intermediaries have succeeded with the principle of freedom of trade, but one must also recognise that the situation has changed since then. The forthcoming greater need for consumer protection as a result of its growing independence in the deregulated market, long-distance supervision by the country of origin and uncontrolled product development require new and different methods.

However, these are not only required for reasons of consumer protection, but also by the insurance intermediaries' right to freedom of services and freedom of establishment throughout Europe. If the Recommendation is not adopted, the other European countries - all of which already have legal regulations governing the profession - will not authorise German insurance intermediaries to transact business in their countries, as our intermediaries' professional competence and registration will not be proven. German intermediaries will thus be excluded. Only by adopting the Recommendation would all insurance intermediaries in Europe - including the German intermediaries - have a valid EC "professional driving licence" for their activities throughout the internal market.

Fortunately the first signs of a better understanding of the situation can be detected in political circles. For example, in the course of a debate about amendments to the Law on Insurance Supervision, the Bundesrat (upper house of parliament) pointed out that in order to implement the EC Recommendation on Intermediaries, a legal framework would be both necessary and appropriate. I therefore hope that it will still be possible to enact such a regulation before the end of 1994.

If the Recommendation is not adopted, we will have to comply with a European Directive that will not take particular national characteristics into consideration. With its Recommendation, the EC Commission has made it very clear how much importance it attaches to consumer protection in the area of insurance intermediaries' activities. A failure to implement the Intermediaries Recommendation will not be met by resignation but by more vigorous measures. A binding Directive would oblige the German parliament to implement 
what Brussels has decided; the industry's existing proven solutions could no longer be integrated and the particular characteristics of the German intermediaries market could no longer be taken into account.

The German insurance industry therefore strongly recommends swift adoption of the Recommendation, both in the interests of the market and - above all - of our customers.

I conclude with a personal comment: in the discussion of this and of similar topics relating to the Europeanization of our common market, the representatives of other countries have shown us time and again how much they are guided by practical considerations and their citizens' expectations. Perhaps it would also be a worthwhile aim for our legislators not to let themselves be guided so strongly by abstract principles but more by those that would facilitate - or indeed guarantee - the functioning of the internal market in Germany as well. What do Germans expect from a partially harmonised insurance market? You too are citizens of this country and you too need insurance cover. In future do you really want to be offered intangible promises of cover, that have not been proven and approved, by untrained, unregistered insurance intermediaries operating under looser insurance supervision? Are we creating a world in which free competition functions or are we flogging the principle of deregulation to death? 